\title{
European reference networks: moving towards a tangible outcome of the European Union's cross-border healthcare directive?
}

\author{
Nadia Kamel \\ Affiliation: European Respiratory Society, EU Affairs Dept, EU Office, Brussels, Belgium.
}

Correspondence: Nadia Kamel, European Respiratory Society, EU Affairs Dept, 49-51 Rue de Tréves, 1040 Brussels, Belgium. E-mail: nadia.kameldersnet.org

@ERSpublications

European Reference Networks is an EU cross border healthcare initiative for improving lives of rare disease patients http://ow.ly/FXmg304q5BR

\section{Introduction}

October 25, 2013 was the deadline for all European Union (EU) countries to transpose the directive on patients' rights in cross-border healthcare, adopted in March 2011, into their national law [1]. The ability of patients and health professionals to move across borders within the EU flows directly from the fundamental freedoms of movement of people and services [2].

The directive on cross-border healthcare has been regarded by many as a major achievement of the policy of "patient empowerment" of the European Commission, granting EU citizens the right to access healthcare services (for planned treatment) in another member state [2]. In summary the aims of this directive are to: 1) clarify and simplify the rules and procedures applicable to patients regarding access and reimbursement for healthcare received in another EU member state; 2) provide EU citizens with better information on their rights; 3) ensure that cross-border healthcare is safe and of high-quality; and 4) promote cooperation between member states.

In reality, however, few citizens in the EU know they can seek healthcare from any of the $28 \mathrm{EU}$ member states, and even fewer of them try. This was clearly shown by a Eurobarometer survey in May 2015 on "Patients' rights in cross-border healthcare in the European Union" [3]. This situation may slowly begin to change, at least for those patients with complex and rare diseases, as, under Article 12 of the same directive, European Reference Networks (ERNs) are currently being formally set-up connecting highly specialised centres at the EU level [4].

The goals for ERNs are to help facilitate access to diagnosis and treatment by centralising knowledge and experience, acting as focal points for medical research and training, and as resources in the area of rare or low prevalence complex diseases or conditions. Some broad thematic ERN proposals that are being discussed within the clinical community cover areas such as rare autoimmune and auto-inflammatory diseases; rare paediatric cancers and tumours; rare hepatic diseases; rare metabolic hereditary disorders; rare urogenital diseases; rare eye diseases; rare bone diseases; rare skin disorders; rare neuromuscular diseases; rare renal diseases; and rare pulmonary diseases. The premise for establishing ERNs is that expertise should be brought closer to the patients' home.

Received: July 122016 | Accepted after revision: Aug 262016

Conflict of interest: N. Kamel is an employee of the European Respiratory Society.

Copyright OERS 2016 


\section{A difficult birth for European cross-border healthcare}

Developments at EU-level in cross-border health policy have been very complex and laborious, with more than a decade of rulings by the Court of Justice of the European Union and years of negotiations between member states, the Commission and the European Parliament [5].

It started in 1998 with citizens bringing a series of cases to the European Court of Justice (ECJ) seeking to assert rights to reimbursement for healthcare provided in other member states and invoking the principles of free movement of goods and services, e.g. the Kohll and Decker cases [6]. Several more ECJ cases followed. Subsequent cases both clarified and complicated the legal situation and it rapidly became clear that there was a need for primary legislation to clarify the evolving, and frequently confusing, situation that was being created by an evolving body of case law [2].

In 2004 the European Commission proposed to codify this case law by including health services in a proposed "services directive". This approach, however, was not accepted by the European Parliament and Council as it was argued that health services are different from commercial services and should not be opened up to the internal (free) market [7]. The services directive was only approved once healthcare was removed from its scope of application [8].

In 2011, after several years of deliberations, the European Parliament and Council adopted the directive on patients' rights in cross-border healthcare, which sought to provide a clear legal framework and resolve ambiguities about the mechanisms involved in providing cross-border care [4]. Unlike the services directive, the cross-border healthcare directive moves away from promoting trade in services to promoting citizens' rights: EU citizens are able to receive reimbursable healthcare in another EU country as long as the type of treatment and costs involved would normally be covered in their own national health jurisdiction [8].

The final result is two parallel procedures that patients can use to receive funding for (planned) treatment received in another EU member state (figure 1). For patients, therefore, either the cross-border healthcare directive applies or the EU regulations on the coordination of social security systems apply [8].

\section{Meanwhile...}

In parallel with these first ECJ rulings on cross-border care, the possibility of creating ERNs for highly specialised clinical services, also referred to as "centres of excellence", "centres of reference" or "centres of expertise" was simultaneously being investigated. The main motivation for their creation was to realise economies of scale and to enact a proactive policy towards cross-border healthcare by common sharing of resources [9].

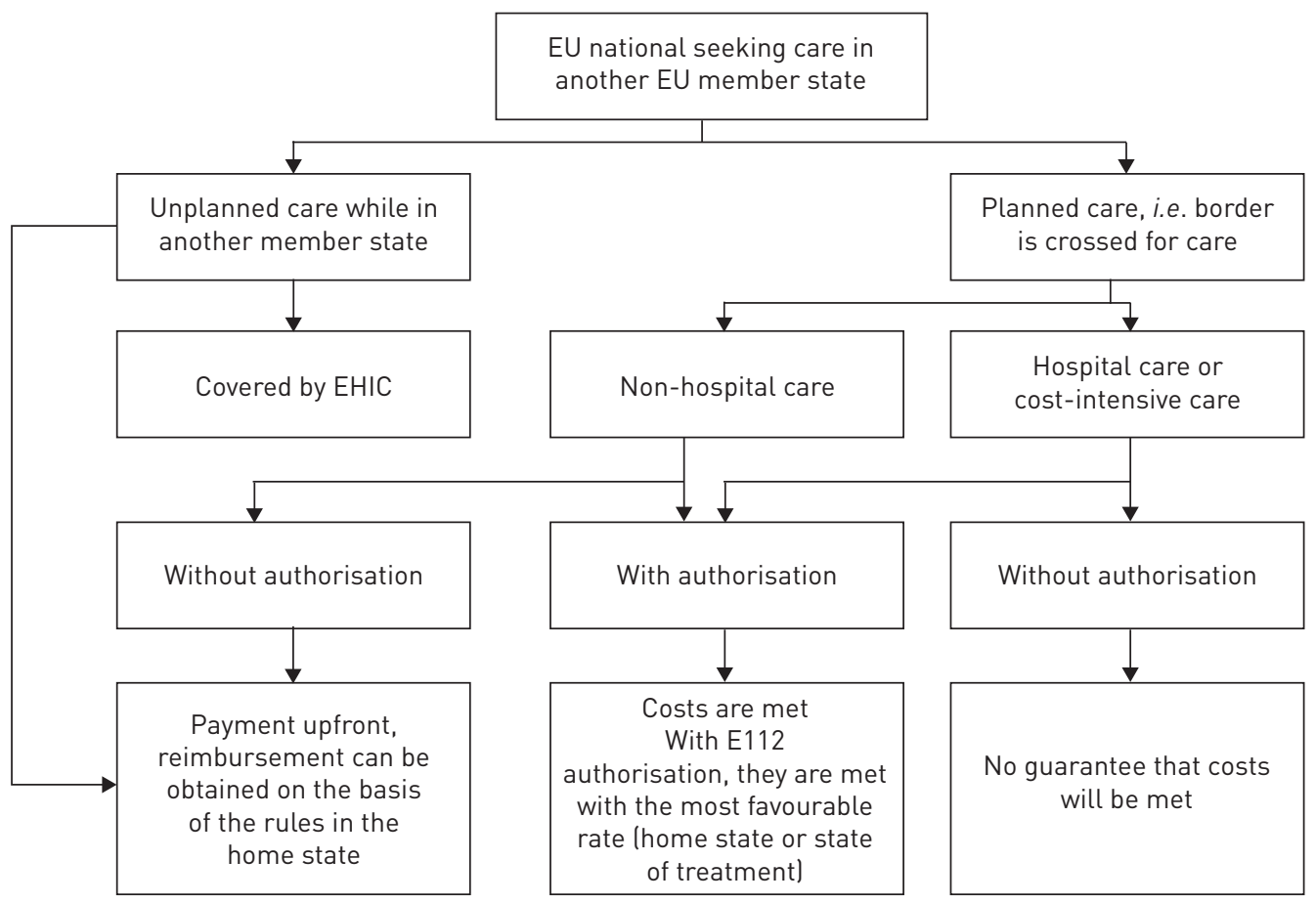

FIGURE 1 Flowchart summarising financing of cross-border care. EU: European Union; EHIC: European Health Insurance Card. Reproduced from [5] with permission. 
In 2005, a specific working party on centres of reference together with another EU task force on rare diseases coordinated their efforts to produce an overview of centres of reference for rare diseases. In 2006 and 2007, the feasibility of various approaches for developing European centres of reference (in rare diseases) was tested in 11 pilot projects funded by the EU's public health programme. Further pilot projects were funded via the EU research framework programmes 5, 6 and 7 [9].

The EU Committee of Experts in Rare Diseases (EUCERD) analysed these pilot projects and summarised them in a report from 2011 entitled "Preliminary Analysis of the outcomes and experiences of pilot European Reference Networks for rare diseases" [10]. Among other items, the report concludes:

"It was also agreed that expertise needs to be identified, and designated, at a national level before networks of expertise at a European level can be built. ERN at European level should most importantly be infrastructures rather than just groups of experts, and should be coordinated by an expert in networking whose position is financed at European level. The type of infrastructures needed at EU level should be explored and the resources that can be mutualised and shared should be identified. Formal systems for sharing experiences should be envisaged. An evaluation system for European Reference Networks should be established to assess their strengths and weaknesses in order to highlight directions for further improvement. This system could be linked to a financial sustainability instrument." [10].

One important issue concerning ERNs that could not be solved by the pilot projects concerned their long-term financial sustainability. Apart from one pilot project that was able to secure sustainable funding (via patient organisations) all others ceased their activities due to a lack of (funding) resources [10].

\section{ERNs: one example of cooperation in healthcare at the EU level}

Chapter IV of the cross-border healthcare directive includes a section on "cooperation in healthcare" which identifies specific areas that could deliver tangible benefits to health systems across the EU such as mutual recognition of medical prescriptions (article 11), European Reference Networks (article 12), rare diseases (article 13), e-health (article 14) and health technology assessment (article 15) [4].

Health systems in the EU seek to provide high-quality, cost-effective care. As stipulated in article 12.1 this is particularly difficult in the case of conditions requiring a concentration of resources or expertise, and even more so for rare or low prevalence complex diseases or conditions [4]. Therefore, the objectives of ERNs are best achievable at EU level.

The concept for an ERN is reflected in its definition in article 12 of directive 2011/24/EU [4]. Instead of providing a clear-cut definition, the article instead lists the objectives and characteristics for ERNs to qualify as such [9]. They can pursue different objectives, but each network should fulfil at least three of the eight objectives set out in article 12.2 of the directive [4]. The stated objectives for these ERNs include: to provide better access of patients to highly specialised and high quality and safe care; to pool knowledge, improving diagnosis and care in medical domains where expertise is rare; to exploit innovations in medical science and health technologies; to facilitate the mobility of expertise, either virtually or physically; and to reinforce research, epidemiological surveillance (e.g. registries) and provide training for health professionals [4].

A first call for interest for ERNs was published on March 16, 2016 with a deadline for submissions of June 21, 2016. Subject to fulfilling the legal provisions for ERNs, any group of at least 10 healthcare providers established in at least eight member states may collectively respond by the deadline with an application containing a proposal to establish a network in a given field of expertise [11]. Healthcare providers wishing to become a member of an ERN need to seek prior endorsement from their national authority in the country in which they are based to participate in an ERN. This endorsement implies legal recognition of the capacity to address the group of diseases the ERN will deal with.

\section{What are the results today for cross-border EU healthcare?}

A commission report, issued on September 4, 2015, on implementation of the cross-border healthcare directive 2 years since its transposition into national law shows that patient flows for healthcare abroad under the directive are low (only $\sim 2 \%$ according to the Eurobarometer survey) [1]. The main reasons cited are: 1) several member states were late implementing the directive; 2) citizens' awareness of their general rights to reimbursement in another EU member state are still extremely low; and 3) a considerable number of member states appear to deliberately be complicating cross-border care, for example, by making the system of prior authorisation more extensive than is justifiable [1]. 
Despite the apparent low uptake of the directive, to date, the European Commission is optimistic as the directive has helped open up other discussions among member states with regards to health reform. Health services in all member states are facing similar pressures, which in turn are leading to an increased interest in making better use of resources via cross-border collaboration. For instance, with regard to the ERNs the Commission report states:

"To take just one example, the European Reference Networks could seriously improve access to care for rare/low-prevalence and complex diseases where expertise is rare. To realise this potential, ongoing support and commitment from all sides will be needed" [1]

In the field of rare respiratory diseases, an "ERN-LUNG" is currently in the process of being set-up and has consolidated the involvement of several core networks representing this broad field including interstitial lung diseases, cystic fibrosis, pulmonary hypertension, primary ciliary dyskinesia, bronchiectasis, $\alpha_{1}$-antitrypsin deficiency, mesothelioma, chronic lung allograft dysfunction, and other rare lung diseases (http://ern-lung.org). The ERN-LUNG network was one among 24 other broad thematic network applications that were received by the European Commission by the closing date of July 22, 2016 (figure 2).

The ERN-LUNG network aims to attain official recognition as an ERN and an EU application was submitted for the June 21, 2016 application deadline. The European Respiratory Society and the European Lung Foundation are supporting the application for an ERN-LUNG network and as important stakeholders are involved in the ERN-LUNG governance structure and advisory board.

\section{Conclusions}

For those networks that will finally be selected and officially recognised as ERNs in late 2016 or early 2017 , the main uncertainty is obviously that concerning their long-term sustainability. This was an issue for nearly all of the previous pilot projects that relied on EU grants to fund their activities.

At the same time, the indications are clear that cross-border healthcare is moving at a fast pace with immense potential to grow in the years ahead. As the Commission's evaluation report suggests, this is not the result of the directive itself, but reflects broader technological and societal changes: citizen's expectations are radically different now than they were just a few years ago (and health services are no exception) [1].

The importance of political will and support at national and local level will be crucial to sustain ERNs over the longer term. Possible other means of funding will, however, at first probably need to be explored (e.g. charities, clinical trials or consultancy activities) [2].
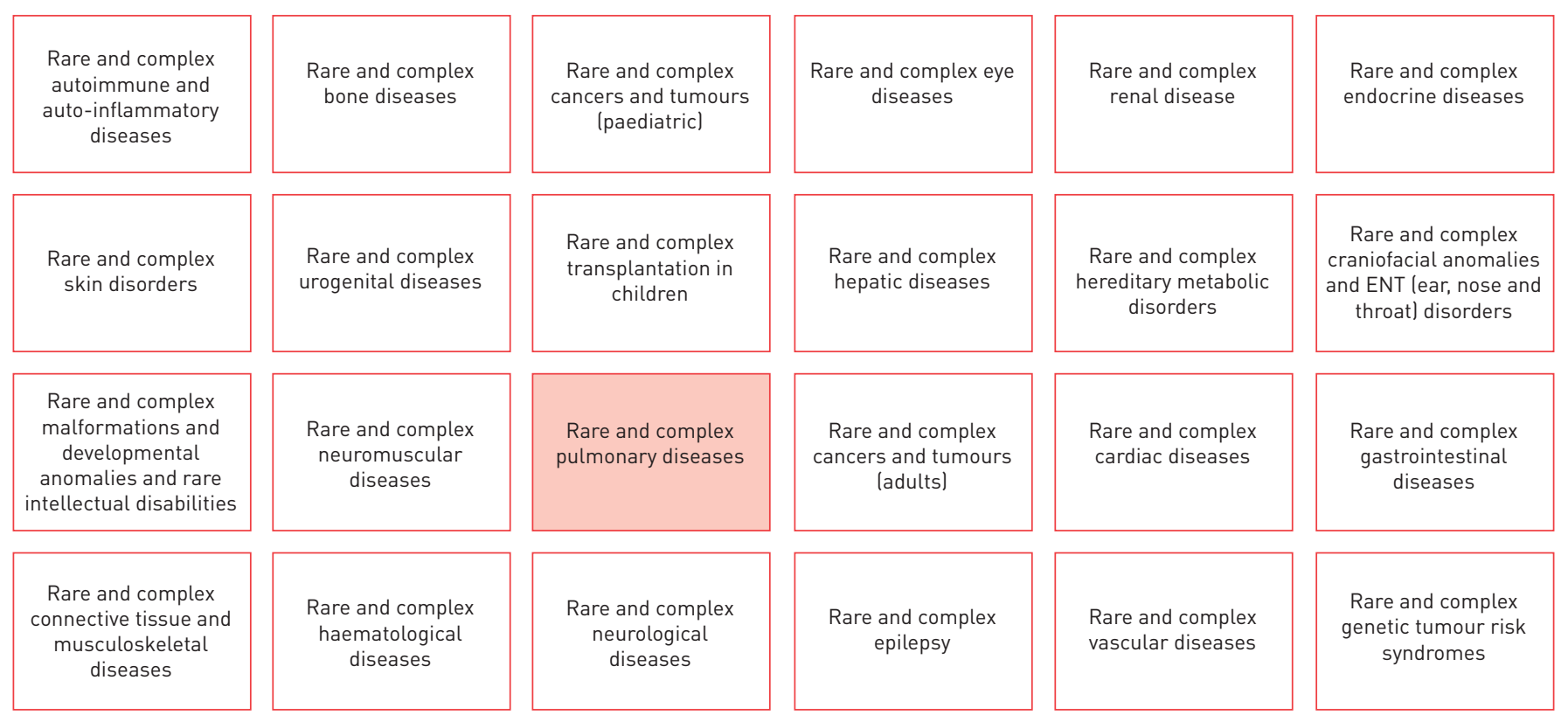
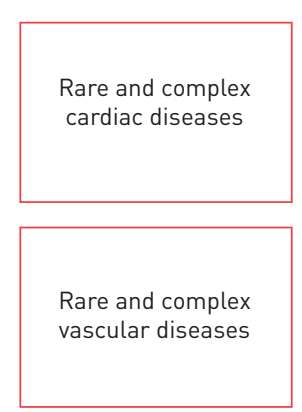
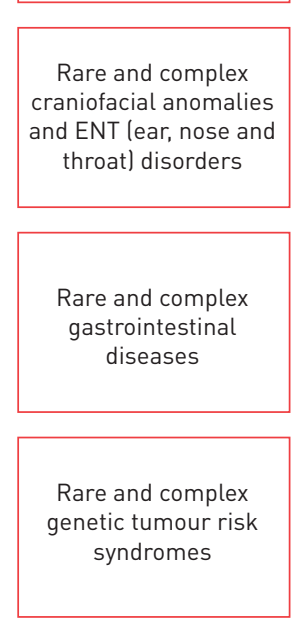

FIGURE 2 European Reference Network applications that were received by the European Commission by 22 July 2016 [12]. Information courtesy of the European Commission. 
Finally, a key factor for the success of this directive and implicitly the ERNs will be the greater efforts deployed by member states to increase EU citizens' awareness of the cross-border healthcare directive and their rights to receive healthcare in another EU member state. In this respect, on May 9, 2016 the European Parliament launched a written declaration procedure on the current situation with regard to the directive [13]. Moreover, the European Commission recently organised a conference about the cross-border directive to strengthen cooperation among the designated National Contact Points in the EU Member States, in cooperation with patient organisations, healthcare providers and healthcare insurers for the benefit of patients [14].

\section{References}

1 European Commission. Report from the Commission to the European Parliament and the Council: Commission report on the operation of Directive 2011/24/EU on the application of patients' rights in cross-border healthcare. http://ec.europa.eu/health/cross_border_care/docs/2015_operation_report_dir201124eu_en.pdf Date last accessed: June 20, 2016. Date last updated: September 4, 2015.

2 European Commission. Expert Panel on Effective Ways of Investing in Health: cross-border cooperation. August 3, 2015. http://ec.europa.eu/health/expert_panel/opinions/docs/009_crossborder_cooperation_en.pdf Date last accessed: June 20, 2016. Date last updated: July 29, 2015.

3 European Commission. Special Eurobarometer 425: patients' rights in cross-border healthcare in the European Union. http://ec.europa.eu/public_opinion/archives/ebs/ebs_425_sum_en.pdf Date last accessed: June 20, 2016. Date last updated: May, 2015.

4 Official Journal of the European Union: Directive 2011/24/EU of the European Parliament and of the Council of 9 March 2011 on the application of patients' rights in cross-border healthcare. OJ L 88, 4.4.2011, pp. 45-65. http:// eur-lex.europa.eu/legal-content/EN/TXT/PDF/?uri=CELEX:32011L0024\&from=EN Date last accessed: June 20, 2016.

5 Palm W, Wismar M, van Ginneken E, et al. Towards a renewed community framework for safe, high-quality and efficient cross-border health care within the European Union. In: Wismar M, Palm W, Figueras J, et al., eds. Cross-border Health Care in the European Union: Mapping and Analysing Practices and Policies. Brussels, European Observatory on Health Systems and Policies, 2011; pp. 23-46. www.euro.who.int/_data/assets/pdf_file/ 0004/135994/e94875.pdf

6 European Commission. Communication from the Commission: a Community framework on the application of patients' rights in cross-border healthcare. http://eur-lex.europa.eu/legal-content/EN/TXT/PDF/?uri=CELEX:52008 DC0415\&from=EN. Date last accessed: June 20, 2016. Date last updated: July 2, 2008.

7 McKee M, Busse R, Baeten R, et al. Cross-border health care collaboration in the European Union: placing the patient at the centre. Eurohealth 2013; 19: 3-5.

8 Footman K, Knai C, Baeten R, et al. Policy Summary 14: cross-border health care in Europe. Copenhagen, World Health Organisation, 2014. www.euro.who.int/_data/assets/pdf_file/0009/263538/Cross-border-health-care-inEurope-Eng.pdf Date last accessed: July 12, 2016.

9 Palm W, Glinos IA, Rechel B, et al. (eds). Building European Reference Networks in Health Care. Brussels, European Observatory on Health Systems and Policies, 2013. www.euro.who.int/_data/assets/pdf_file/0004/ 184738/e96805-final.pdf Date last accessed: July 12, 2016.

10 European Union Committee of Experts on Rare Diseases (EUCERD). Preliminary analysis of the outcomes and experiences of pilot European Reference Networks for rare diseases. http://ec.europa.eu/health/rare_diseases/docs/ eucerd2011_report_european_ref_net.pdf Date last accessed: July 12, 2016. Date last updated: May, 2011.

11 European Commission, Public Health. European Reference Networks. http://ec.europa.eu/health/ern/ implementation/call/index_en.htm Date last accessed: July 12, 2016.

12 European Commission. European Reference Networks: preliminary results of call for interest. http://ec.europa.eu/ dgs/health_food-safety/dyna/enews/enews.cfm?al_id=1712 Date last accessed: October 12, 2016. Date last updated: September 20, 2016.

13 European Parliament. Written Declaration submitted under Rule 136 of the Rules of Procedure on increasing citizens' awareness in relation to the EU directive on cross-border healthcare. 0054/2016. www.europarl.europa.eu/ plenary/en/written-declarations.html Date last accessed: July 12, 2016. Date last updated: May 9, 2016.

14 European Commission. Brussels, 24 October 2016. Conference on Cross-border Healthcare Directive "Towards amplified awareness of EU rights to cross-border care". http://ec.europa.eu/health/cross_border_care/events/ev_ 20161024_en.htm\#c Date last accessed: October 27, 2016. 